\title{
Judgments toward women wearing high heels: a forced-choice evaluation
}

\author{
Nicolas Guéguen*, Jordy Stefan and Quentin Renault
}

\author{
${ }^{*}$ Correspondence: \\ nicolas.gueguen@univ-ubs.fr \\ Vannes, France
}

\begin{abstract}
Research reported that men interact with women wearing high heels more readily than with the same women wearing flat heels. However, the effect of heels on the judgment of women by both men and women has received little attention. Male and female participants viewed two photographs of the same woman's body profile; the woman wore high heels in the one and flat heels in the other, although her shoes and feet were not visible. Participants were asked to select one photograph of the woman on several dimensions of body attractiveness. A significant greater number of male and female participants selected the target with high heels as the sexier, the prettier, and the more elegant, with the more attractive legs and buttocks. The same target was also perceived as the younger person and the photograph that would be preferred by others and the more appropriate for a photo album. The findings support the assumption that high heels could act as secondary sexual characteristics that increase the attractiveness of women to men.
\end{abstract}

Keywords: Women, Attractiveness, Heels

\section{Introduction}

The scientific literature has indicated that across all cultures, men care more about physical features in potential opposite-sex mates than women (Buss 1989; Kenrick et al. 1993; Shackelford et al. 2005). Women's physical attractiveness is important to men, and research has shown that features of clothing appearance are an important factor to judge the physical attractiveness of women.

\section{Women's clothing cues and attractiveness to men}

Research has shown that men judge women differently depending on their clothing appearance. Abbey (1987) observed that men judge the appearance of a woman wearing a low-cut top, shorts, tight jeans, and no bra as an indication of her sexual receptiveness. Similarly, Koukounas and Letch (2001) reported that an actress wearing revealing clothing was perceived by male observers as having greater sexual intent whereas no difference was reported with female observers. Studies have indicated that female targets who wore revealing clothing were rated by men as more seductive and sexier than targets wearing non-revealing clothing (Abbey et al. 1987). Suggestive clothing also appears to influence men's behavior. Guéguen (2011) asked two female confederates (one wearing suggestive clothes and one wearing more conservative clothes) to sit in a tavern and

(c) 2016 Guéguen et al. This article is distributed under the terms of the Creative Commons Attribution 4.0 International License (http://creativecommons.org/licenses/by/4.0/), which permits unrestricted use, distribution, and reproduction in any medium, provided you give appropriate credit to the original author(s) and the source, provide a link to the Creative Commons license, and indicate if changes were made. 
observed the behavior of nearby men. Findings showed that the time the men took to approach the women was significantly shorter in the suggestive clothing condition and that men rated their chances to have a date and to have sex significantly higher in that condition.

Research has also shown that one single cue of clothing appearance, such as the color red, can influence the perceived attractiveness of women to men. Guéguen (2012) observed that women hitchhikers wearing a red tee-shirt obtained a higher response in the number of male drivers who stopped to offer a ride; the color, however, had no effect on female drivers. Pazda et al. (2012) found that men perceived women wearing red as more sexually receptive. Niesta Kayser et al. (2010) observed that men who viewed an ostensible conversation partner in a red as opposed to a green shirt chose to ask her more intimate questions, and they chose to sit closer to a woman wearing a red shirt rather than a blue shirt.

Overall, the studies mentioned above show that men's behavior and judgment of women are related with women's clothing appearance. Our objective was to evaluate an aspect of clothing appearance that has received little interest in the literature: shoes and shoe heels in particular. Popular magazines have frequently associated high-heeled shoes with female sex-appeal and attractiveness. Adult magazines and films have also used a host of models with high-heeled shoes.

\section{Women's high heels and attractiveness to men}

Several studies have warned that wearing high heels can cause pain, long-term foot damage, and risk of accidental trauma (Cronin et al. 2012; Saltzman 1998; Smith 1999). Nevertheless, many women worldwide wear high-heeled shoes. For Smith (1999) and Smith and Helms (1999), high heels could act as secondary sexual characteristics that could increase the attractiveness of women to men. Wearing high heels could emphasize the physical attractiveness of a woman, and psychosocial studies have consistently shown that men judge and react differently toward women according to their clothing appearance (Guéguen 2012; Pazda et al. 2012; Niesta Kayser et al. 2010). Recent studies examining the effect of women's heel length on men have confirmed that high heels increase women's attractiveness to men. Morris et al. (2013) recorded women walking in flat shoes and high heels, but their study participants viewed only point-light videos of the women walking. The authors reported that the participants evaluated the gait of the targets in the high-heel condition as significantly more attractive than that of the women in the flat-heel condition. The authors also analyzed the biomechanical changes produced by heel length on women's gait and found that heels altered the women's gait, reducing stride length and increasing pelvis tilt and hip rotation.

Morris et al. (2013) and Smith and Helms (1999) stated that women probably use high heels to artificially increase their femininity and to become more attractive to men. Field studies recently conducted confirmed that men approach women wearing high heels more readily (Guéguen 2015; Guéguen and Stefan 2015). In a series of studies conducted by these authors, women confederates wearing shoes with 0-, 5-, or 9-cm heels asked men for help in various circumstances (asking men to participate in a survey, dropping a glove and apparently unaware of the loss, etc.). Findings showed that men's helping behavior increased with the increase of heel length of the confederates, but that heel 
length had no effect on women's helping behavior. In a further study, it was al observed that men smiled more often to women with high heels they passed in a street and that they spontaneously approached women more quickly in a bar when the latter wore highheeled shoes. Guéguen and Stefan (2015) stated that change in gait, foot-size judgment, and misattribution of sexiness and sexual intent could explain men's behavior.

\section{Rationale of the study and hypothesis}

These first studies examining the effect of women's shoe heels on men have thus consistently shown that high heels increase women's attractiveness to men. The purpose of this study was to increase understanding of how women wearing high heels are perceived in order to explain why men's behavior changes depending on the presence of high heels on women's feet. In this experiment, the same woman was presented with or without high heels (although her shoes were not visible), and the participants were asked to evaluate which target they preferred on several dimensions associated with physical appearance. It was hypothesized that the target with high heels would be perceived as the attractive one more often.

\section{Method}

\section{Participants}

The participants were 51 men and 59 women. The average age of the participants was 20 , ranging from 18 to 22 years of age. Both male and female participants were undergraduate students in business who were enrolled in the same course, in the same university team, and who came from the same geographical area of the south-west Atlantic coast in France. All were Caucasian.

\section{Material}

Two photographs of the same 20-year-old woman were used as targets in this experiment. The woman wore a black tee-shirt and a short skirt; on the one photograph, she wore shoes with 9-cm heels (high-heel condition) whereas on the other one, she wore flat shoes (flat-heel condition). Her posture, position, and the place where the photographs were taken remained the same. Only the body profile of the woman target appeared, from the top of her shoulder to the middle of her calf. The photographs were printed in black and white on white paper.

\section{Procedure}

A laboratory assistant went to the university library and asked students to participate in an experiment whereby they would view two photographs of the same woman and select the photograph that was the most representative on several dimensions. If the students agreed, they received a sheet of paper with the two photographs printed on the top half of the sheet. One of the photographs was labelled "A," and the other was labelled "B." The order of the photographs varied for each participant. On the bottom half of the sheet, there were several questions associated with the evaluation of the target's physical appearance: sexiness, beauty, leg attractiveness, buttock attractiveness, elegance. The participants were also asked to determine which of the targets was the younger. These questions were used because most of the studies examining features of physical 
appearance of women used such items to evaluate the targets [i.e., (Graham and Jouhar 1981; Swami and Barrett 2011)].

For each question, the participant was instructed to select which of the photographs showed the woman who was the sexier, the more elegant, and so on for each dimension. Three responses were offered: A, B, or "no difference." Two more questions were added, asking which of the photographs would be preferred by other individuals and which of the photographs the participant would choose for a photo album. After responding, the participants were asked what they thought the purpose of the study and the masked difference between the two photographs were. Only one man mentioned the shoe heels, and his data were not used in the analysis.

\section{Results and discussion}

The participants' target choices by gender are shown in Table 1 .

With all the measures, a Chi square goodness-of-fit test was performed in order to assess whether there was a significant difference or not between the three possible choices offered to the participants. The results of the tests conducted with both male and female participants showed a highly significant effect on all the dimensions measured. A greater number of participants selected the target with high heels as the sexier, the prettier, and the more elegant, with the more attractive legs and buttocks. The same target was also perceived as the younger person and the photograph that would be preferred by others and the more appropriate for a photo album.

Table 1 Models selected by the participants

\begin{tabular}{|c|c|c|c|c|}
\hline Measure & High heels & Flat heels & No difference & Statistical difference \\
\hline \multicolumn{5}{|l|}{ Sexiness } \\
\hline Male participants & $88.2 \%$ & $5.9 \%$ & $5.9 \%$ & $x^{2}(2)=69.18, p<.001$ \\
\hline Female participants & $81.4 \%$ & $5.1 \%$ & $13.6 \%$ & $x^{2}(2)=61.86, p<.001$ \\
\hline \multicolumn{5}{|l|}{ Prettier legs } \\
\hline Male participants & $62.7 \%$ & $13.6 \%$ & $28.8 \%$ & $x^{2}(2)=22.24, p<.001$ \\
\hline Female participants & $57.6 \%$ & $9.8 \%$ & $27.5 \%$ & $x^{2}(2)=17.73, p<.001$ \\
\hline \multicolumn{5}{|l|}{ Prettier buttocks } \\
\hline Male participants & $54.9 \%$ & $9.8 \%$ & $35.3 \%$ & $x^{2}(2)=15.65, p<.001$ \\
\hline Female participants & $55.9 \%$ & $1.7 \%$ & $42.4 \%$ & $x^{2}(2)=28.20, p<.001$ \\
\hline \multicolumn{5}{|l|}{ More elegant } \\
\hline Male participants & $88.2 \%$ & $5.9 \%$ & $5.9 \%$ & $x^{2}(2)=69.18, p<.001$ \\
\hline Female participants & $91.5 \%$ & $1.7 \%$ & $6.8 \%$ & $x^{2}(2)=90.14, p<.001$ \\
\hline \multicolumn{5}{|l|}{ More good-looking } \\
\hline Male participants & $80.4 \%$ & $5.9 \%$ & $13.7 \%$ & $x^{2}(2)=51.29, p<.001$ \\
\hline Female participants & $67.8 \%$ & $5.1 \%$ & $27.1 \%$ & $x^{2}(2)=35.83, p<.001$ \\
\hline \multicolumn{5}{|l|}{ Younger } \\
\hline Male participants & $68.6 \%$ & $11.8 \%$ & $19.6 \%$ & $x^{2}(2)=29.06, p<.001$ \\
\hline Female participants & $62.7 \%$ & $5.1 \%$ & $32.2 \%$ & $x^{2}(2)=29.42, p<.001$ \\
\hline \multicolumn{5}{|l|}{ Selected by others } \\
\hline Male participants & $86.3 \%$ & $5.9 \%$ & $7.8 \%$ & $x^{2}(2)=64.35, p<.001$ \\
\hline Female participants & $89.8 \%$ & $6.8 \%$ & $3.4 \%$ & $x^{2}(2)=84.85, p<.001$ \\
\hline \multicolumn{5}{|l|}{ Selected for an album } \\
\hline Male participants & $86.3 \%$ & $7.8 \%$ & $5.9 \%$ & $x^{2}(2)=64.35, p<.001$ \\
\hline Female participants & $78.0 \%$ & $6.8 \%$ & $15.3 \%$ & $x^{2}(2)=53.53, p<.001$ \\
\hline
\end{tabular}


All the results reported were observed with both male and female participants, and the results of a statistical analysis examining the effect of participant gender on the choices of the targets showed participant gender to be non-significant. This non gender effect in the evaluation was congruent with the findings found by Morris et al. (2013) who presented women walking in flat shoes and high heels with the help of point-light videos of the women walking. The authors reported that both male and female participants evaluated the gait of the targets in the high-heel condition as significantly more attractive than the women in the flat-heel condition.

Our findings clearly show that the profile of the woman target photographed when she was wearing high heels was selected as the more attractive physically by both male and female participants. Significantly, the participants were not conscious of the difference between the two photographs used in this experiment.

Such results are in line with the findings reported by Guéguen (2015) and Guéguen and Stefan (2015) who observed in several studies that men approached a woman wearing high heels more readily. Our results were also congruent with the findings of Morris et al. (2013) who reported that women wearing high heels were perceived as more feminine. However, in these studies, most of the women targets were walking, and research has shown that the nonverbal behavior of women, including gait, was associated with variations in men's judgments of attractiveness and behavior (Guéguen 2010; Moore 1985; Moore \& Butler 1989; Walsh \& Hewitt 1985). It has also been found that the attractiveness of gait varied with the target's age (Montepare \& Zebrowitz-McActur 1988), with younger walkers rated higher in sexiness and happiness. High heels could have influenced the women's gait or posture, which in turn influenced their attractiveness to men. However, the present study findings regarding a static target show that a change in the gait is clearly not the only factor that could explain why women are perceived as more attractive when wearing high heels. Fessler et al. (2005) reported that the small foot size of female targets increased their attractiveness to men, but in our study, the target's feet were not visible. Men's preference for women with morphological traits associated with youthfulness (Buss 1994; Symons $1995)$ is confirmed in our study, as the target with high heels was perceived as younger than the target with no heels, which suggests that heels could increase the perceived youthfulness of women.

Thus, overall, these new findings expand those reported by Morris et al. (2013), Guéguen (2015), and Guéguen \& Stefan (2015). We also found that the legs and the buttocks of the woman were perceived more positively when she was wearing high heels. It thus seems that the appearance of the body profile, and not only the gait, becomes more attractive when a woman wears high heels. This positive effect on body judgment was also found with the female participants.

Smith (1999) and Smith and Helms (1999) stated that high heels act as secondary sexual characteristics that could increase the attractiveness of women to men. Even if high heels do increase the femininity of the gait, our findings show that other aspects of body appearance are also affected by shoe heels, even when the heels are not seen. After analyzing the cover photographs of pornographic magazines, Dietz and Evans (1982) reported that over $50 \%$ of the female models wore high heels. Thus, men could falsely attribute sexual intent to women wearing high heels. Since in our study the target's shoe 
heels were not visible, this connotation or misattribution of sexual intent cannot account for our findings.

While Morris et al. (2013) showed that the gait of women wearing high heels is perceived to be more feminine, our findings suggest that high heels also increase the attractiveness of women's morphological and body traits. Previous studies examining posture and judgments of attractiveness have reported that postural appearance influenced judgment. Gitter et al. (1982) instructed participants to examine drawings of male physiques manipulating five somatic and postural dimensions of appearance (abdomen, shoulder, neck, head, and body shape). They reported that the abdomen factor was responsible for the largest percentage of the variance; a protruding abdomen was associated with negative ratings, whereas its absence was associated with the most positive ratings. Osborn (1996) also examined color photographs of Caucasian women with slumped, normal, or military attention-style standing posture. This author observed that the slumped target was perceived to have more medical problems, to be less fertile, less likely to have an extramarital affair, and less attractive physically. In this study as in our own study, the target was static, which could suggest that wearing heels is associated with changes in women's posture that are perceived more positively in a large range of dimensions.

Hence, the impact of heels appears to be twofold: first, heels change the gait of a woman, hence change judgments of her attractiveness when she walks; second, heels also change her posture and body when she remains static. This could explain why men approach women with high heels more readily, and why women wear high heels even if back or foot damage is associated with walking in high-heeled shoes (Cronin et al. 2012; Saltzman 1998; Smith 1999). Wearing high heels could be an element of mate selection for women who thus increase their attractiveness to men and decrease the competition with other women.

\section{Conclusion}

In conclusion, the findings reported in this study showed that a woman wearing high heels was selected as the sexier, prettier, younger, the more elegant and with the more attractive legs and buttocks. These results was reported even if the participants could not see her shoes and feet. The same pattern of findings was reported both with male and female participants suggesting that wearing high heels increased overall attractiveness of the target. Such findings also support the assumption that high heels could act as secondary sexual characteristics that increase the attractiveness of women to men.

Authors' contributions

All authors read and approved the final manuscript.

Competing interest

On behalf of all authors, the corresponding author states that there is no competing interest.

Received: 17 September 2015 Accepted: 14 January 2016

Published online: 08 February 2016

References

Abbey, A. (1987). Misperception of friendly behavior as sexual interest: a survey of naturally occurring incidents. Psychol Women Q, 11, 173-194.

Abbey, A., Cozzarelli, C., McLaughlin, K., \& Harnish, R. J. (1987). The effects of clothing and dyad sex composition on perceptions of sexual intent: do women and men evaluate these cues differently. J App/ Soc Psychol, 12, 108-126. 
Buss, D. M. (1989). Sex differences in human mate preferences: evolutionary hypotheses tested in 37 cultures. Behav Brain Sci, 12,1-49.

Buss, D. M. (1994). The evolution of desire: strategies of human mating. New York: Basic Books.

Cronin, N., Barrett, R., \& Carty, C. (2012). Long-term use of high-heeled shoes alters the neuromechanics of human walking. J Appl Physiol, 112, 1054-1058.

Dietz, P., \& Evans, B. (1982). Pornographic imagery and prevalence of paraphilia. Am J Psychiatry, 139, 1493-1495.

Fessler, D. T., Nettle, D., Afshar, Y., de Andrade Pinheiro, I., Bolyanatz, A., Mulder, M. B., \& Zbarauskaite, A. (2005). A crosscultural investigation of the role of foot size in physical attractiveness. Arch Sex Behav, 34, 267-276.

Gitter, A. G., Lomranz, J., \& Saxe, L. (1982). Factors affecting perceived attractiveness of male physiques by American and Israeli students. J Soc Psychol, 118, 167-175.

Graham, J. A., \& Jouhar, A. J. (1981). The effects of cosmetics on person perception. Int J Cosmet Sci, 3, 199-210.

Guéguen, N. (2010). The effect of a woman's incidental tactile contact on men's later behavior. Soc Behav Pers, 38, 257-266.

Guéguen, N. (2011). The effect of women's suggestive clothing on men's behavior and judgment: a field study. Psychol Reports, 109, 635-638.

Guéguen, N. (2012). Color and women hitchhikers'attractiveness: gentlemen drivers prefer red. Color Res Appl, 37(1), $76-78$.

Guéguen, N. (2015). High heels increase women's attractiveness. Arch Sex Behav, 44, 2227-2235. doi:10.1007/ s10508-014-0422-z.

Guéguen, N., \& Stefan, J. (2015). Men's judgment and behavior toward women wearing high heels. J Hum Behav Soc Environ, doi:10.1080/10911359.2014.976697.

Kenrick, D. T., Groth, G. E., Trost, M. R., \& Sadalla, E. K. (1993). Integrating evolutionary and social exchange perspectives on relationships: effects of gender, self-appraisal, and involvement level on mate selection criteria. J Pers Soc Psychol, 64, 951-969.

Koukounas, E., \& Letch, N. M. (2001). Psychological correlates of perception of sexual intent in woman. J Soc Psychol, 141, 443-456.

Montepare, J. M., \& Zebrowitz-McArthur, L. (1988). Impressions of people created by age-related qualities of their gaits. J Pers Soc Psychol, 55, 547-556.

Moore, M. M. (1985). Nonverbal patterns in women: context and consequences. Ethol Sociobiol, 6, 237-247.

Moore, M. M., \& Butler, D. L. (1989). Predictive aspects on nonverbal courtship behavior in women. Semiotica, 3, $201-214$.

Morris, P. H., White, J., Morrison, E. R., \& Fisher, K. (2013). High heels as supernormal stimuli: how wearing high heels affects judgments of female attractiveness. Evol Hum Behav, 34, 176-181.

Niesta Kayser, D., Elliot, A. J., \& Feltman, R. (2010). Red and romantic behavior in men viewing women. Eur J Soc Psychol, 40, 901-908.

Osborn, D. R. (1996). Beauty is as beauty does? Makeup and posture effects on physical attractiveness judgments. J App/ Soc Psychol, 26, 31-51.

Pazda, A. D., Elliot, A. J., \& Greitemeyer, T. (2012). Sexy red: perceived sexual receptivity mediates the red-attraction relation in men viewing women. J Exp Soc Psychol, 48, 787-790.

Saltzman, L. M. (1998). A history of medical scientists on high heels. Int J Health Serv, 28, 201-205.

Shackelford, T. K., Schmitt, D. P., \& Buss, D. M. (2005). Universal dimensions of human mate preferences. Pers Individ Differ, 39, 447-458.

Smith, E. O. (1999). High heels and evolution: natural selection, sexual selection and high heels. Psychol Evol Gend, 30 , 245-277.

Smith, E. O., \& Helms, W. S. (1999). Natural selection and high heels. Foot Ankle Int, 20, 55-57.

Swami, V., \& Barrett, S. (2011). British men's hair color preferences: an assessment of courtship solicitation and stimulus ratings. Scand J Psychol, 52, 595-600.

Symons, D. (1995). Beauty is in the adaptations of the beholder: the evolutionary psychology of human female sexual attractiveness. In P. R. Abramson, S. D. Pinkerton, P. R. Abramson, \& S. D. Pinkerton (Eds.), Sexual nature, sexual culture (pp. 80-119). Chicago: University of Chicago Press.

Walsh, D. G., \& Hewitt, J. (1985). Giving men the come-on: effect of eye contact and smiling in a bar environment. Percept Motor Skills, 61, 873-874.

\section{Submit your manuscript to a SpringerOpen ${ }^{\circ}$ journal and benefit from:}

- Convenient online submission

- Rigorous peer review

- Immediate publication on acceptance

- Open access: articles freely available online

- High visibility within the field

- Retaining the copyright to your article

Submit your next manuscript at $\mathbf{s p r i n g e r o p e n . c o m ~}$ 